\title{
Fostering a Culture of Performance Management in Municipalities: Perceptions of Municipal M \& E
} Practitioners in Kwazulu Natal

\author{
Paul Kariuki, Purshottama Reddy \\ University of Kwa Zulu-Natal Westville Campus, South Africa \\ reddyp1@ukzn.ac.za, paulk@ddp.org.za
}

\begin{abstract}
Creating a culture that considers monitoring and evaluation as an essential tool for performance improvement is not an easy task. Some employees are likely to resist due to a lack of awareness of the value of monitoring and evaluation while others could do so due to fear of the accountability and transparency implicit in the implementation of such a system. Nonetheless, it is imperative that performance management is prioritised in municipal development interventions. This article is based on a doctoral study that used qualitative participatory research techniques to gather data from evaluation practitioners' municipalities in KwaZulu-Natal. It presents these practitioners' perspectives on fostering a culture of performance management in local government. The article expounds on their lived experiences that reflect on how performance management could facilitate an effective monitoring and evaluation culture within this sector. The study found that monitoring and evaluation practitioners were sloppy towards their responsibilities and this contributed to poor tracking of the impact of municipal interventions, thereby compromising their abilities to fulfil their constitutional mandates. Furthermore, the study found that there is no political will to enforce performance in most municipalities. The implication of this study is that a culture of performance management must be enforced by government as a critical institutional norm towards achieving accountable, effective, efficient and responsive developmental local government. Municipalities must harness the necessary political will for this to become a reality in municipalities towards promoting good governance in local government supported by a culture of performance.
\end{abstract}

Keywords: Performance Management; Monitoring and Evaluation; South Africa.

\section{Introduction}

Performance management is critical for developmental local government. It creates a performance culture that ensures that a municipality is doing what it is constitutionally mandated to do and is responsive to the needs of its constituents. Efficient and effective service delivery is critical in advancing democracy in South Africa and in ensuring that all citizens have access to basic services. This requires a performance system that facilitates continuous assessment of progress in achieving set targets as well as on-going monitoring and evaluation (M \& E) of municipal systems and structures to ensure that they are responsive to citizens' needs. All these processes should be consistent with government development plans such as the Integrated Development Plan (IDP), the Provincial Growth and Development Strategy (PGDS) and the National Development Plan (NDP) together with operational budgets to ensure that set targets are realized.

Against this background, municipalities must be conscious of performance management to enhance their efficiency and efficacy. Any instances of under-performance or continuous non-performance must be addressed immediately, through legislated processes to ensure that the social contract between government and citizens is honoured. An organization's achievements depend on its employees' level of performance. However, given that the notion of managing performance in municipalities is relatively new, gaps remain in understanding its meaning, implementation and the challenges associated with the practice. The article begins by presenting working definitions of key terminology followed by an exploration of $\mathrm{M}$ \& $\mathrm{E}$ practitioners' understanding of performance management in the second section. Section three discusses what is and what is not working as far as performance management is concerned. The fourth section devises a framework to facilitate useful engagement of performance management by M \& E practitioners.

\section{Definition of Key Terminology}

Performance: For the purposes of this article, performance is defined as the art of managing public programmes to meet set objectives (Bussin, 2017). Other scholars such as Van der Waldt (2014) and Sonnentag and Frese (2003) conceptualize performance as productivity, implying that the term connotes far 
more than doing work; it also incorporates the notions of efficiency and effectiveness, linking an intervention's strategic goals to customer satisfaction and measuring outcomes. However, Mercer (2015) argues that performance should not be limited to action (the behaviour of an individual) but should be extended to encompass the outcome. The behavioural aspect refers to what an individual does at work whilst the outcome involves judgement or evaluation of the quality of the work and the individual's demeanour while doing the work he/she is hired to perform. The evaluation should also consider external factors such as the work environment (supportive or non-supportive), and employee remuneration and job satisfaction, to mention but a few. This article adopts this multidimensional view of performance. While contextual factors may not directly affect the core of an individual's work, they contribute significantly to the achievement of overall organisational goals, vision and mission. They include an individual's capacity to work in a team and contribute to improved organisational procedures and practices.

Performance Management: In this article, performance management refers to a continuous process by which organizational leadership plans, monitors and reviews an employee's work to ensure that it contributes to the realisation of the organizational vision (Hellqvist, 2011). The main objective of managing performance is to ensure that employees' performance is made explicit. It ensures that employees receive ongoing feedback on their work and are provided with continuous skills development to ensure that they are on track.

Benefits of Linking Performance Management to the Organisational Vision: Nixon (2011) notes that, when employees' performance is linked to the organizational vision and mission, this often leads to:

- Enhanced motivation among employees to work better and in a more dedicated manner;

- Increased self-esteem among employees;

- Increased organizational support for employees through on-going feedback, mentoring and coaching;

- Improved leadership practices as management gains insights into their junior colleagues;

- Employees gain insights on what it takes to be an effective individual in their organisation, especially in terms of job clarity and management expectations;

- Employees also gain insights about their capabilities and can develop their own professional development plans, thereby enhancing their competencies;

- An effective performance management system enables management to determine aspects such as salary increases based on merit, promotions and transfers as well as contract termination if there is consistent under-performance;

- Connected to the above, over time, as an organisation improves its performance management system, its goals are made clear and supervisors' feedback is communicated more clearly and timeously. In turn, employees can make sense of how their individual performance contributes to organisational success;

- Protection from potential litigation. An established performance management system gathers data that can demonstrate compliance with labour legislation. In the absence of such systems, performance assessments are arbitrary opening the organisation to the risk of litigation should an employee be dissatisfied with the process, especially if it leads to termination of their services.

Dangers of Weak Links Between Performance Management and the Organisational Vision: Aquinas (2013) identifies the following consequences of weak links between performance management and the organisational goals and vision:

- High staff turnover, especially if employees perceive that performance management is discriminatory. They withdraw emotionally or psychologically and reduce their efforts whilst searching for better employment;

- As noted earlier, where there is no performance management system, arbitrary performance assessments can expose the organisation to unnecessary litigation, especially if the assessment adversely affected an employee;

- Interpersonal relationships at work can be severely strained as employees associate performance evaluation with punishment and discrimination. The relationship between supervisors and subordinates can be strained resulting in inability to deliver on the organisational mandate; 
- Personal biases can replace organisational standards, negatively affecting the legitimacy of the entire performance management system;

- Connected to this point, poorly managed systems waste time and resources as by their very nature performance assessments are time consuming and expensive;

- Employees' motivation to perform at maximum level is reduced or even lost over time;

- Thereafter, job dissatisfaction sets in, resulting in reduced organisational performance and capacity to deliver on its vision. An organization is only as great as its workforce. Demoralised human resources will not deliver high quality services;

- Connected to the above point, organisational standards may start to fall, resulting in negative branding among its peers and possibly decreased funding to implement interventions.

Table 1: Benefits of Linking Performance Management Systems to the Organisational Vision/Mission and Weak Links Consequences

\begin{tabular}{|c|c|}
\hline Benefits & Consequences of Weak Links \\
\hline Improved enthusiasm towards better performance & Lower self-esteem \\
\hline Enhanced confidence & Wasted time and money \\
\hline Managers gain insight about their assistants & Damaged relationships \\
\hline Job definitions and criteria are clarified & Decreased motivation to perform \\
\hline $\begin{array}{l}\text { Enhanced self-insight and development } \\
\text { More fair and appropriate labour practices }\end{array}$ & $\begin{array}{l}\text { Employees suffer job burnout and job } \\
\text { dissatisfaction }\end{array}$ \\
\hline Organisational goals are made clear & Heightened possibilities of being sued by employees \\
\hline $\begin{array}{l}\text { Employees become more competent } \\
\text { Better protection from any forms of litigation }\end{array}$ & $\begin{array}{l}\text { Administrators use an unjustified amount of } \\
\text { resources }\end{array}$ \\
\hline $\begin{array}{l}\text { On time distinction between good and poor } \\
\text { performers }\end{array}$ & $\begin{array}{l}\text { Standards and ratings vary and are unfair } \\
\text { Biases can replace standards }\end{array}$ \\
\hline $\begin{array}{l}\text { Organizational leaders' views of performance are } \\
\text { communicated explicitly }\end{array}$ & $\begin{array}{l}\text { Mystery surrounds how ratings were derived } \\
\text { False or misleading information may be used }\end{array}$ \\
\hline
\end{tabular}

Source: Aquinas (2013)

Performance Management in Local Government: Underpinning Concepts: In the past decade, South African local government's performance has been severely dented by growing maladministration, characterized by chronic corruption, high staff turnover and poor service delivery (Kariuki, 2017). This is an antithesis to the development envisioned in various development plans. The social contract between citizens and the state can only be fully realised if local governance delivers on its mandate as enshrined in the Constitution. The key question is thus, in assessing the effectiveness of local governance, how should its performance be measured? Stated differently, what should be evaluated to determine that a municipality is effective in its work? Van der Waldt (2006) identifies the following crucial elements in analysing the role of local government:

Persuasion: Encompasses information, research and communication. The assumption is that the role of local government in disseminating information is never unbiased.

Finances: Entails revenue collection as well as financial strategies, all of which are authoritative policy instruments.

Rules: Encompass making rules and enforcing them.

Organisation: Necessitates direct delivery of goods and services provision by government or through partnerships with the private sector.

In executing the above responsibilities, local government is expected to perform at the optimal level. The Constitution, Act 106 of 1996, stipulates that all spheres of governance, including local government, should abide by the following principles in delivering services to citizens:

- Government services must be responsive to citizen's needs;

- Services must be provided fairly and impartially; 
- Government resources must be used resourcefully, effectively and economically;

- Public participation ought to be at the centre of all engagements to ensure that citizens' voices are heard and they are meaningfully involved in decision making;

- Government at all levels must remain accountable, transparent and development-oriented.

Given this background, citizens' expectations of local government performance are:

- Government services will be provided expediently and equitably;

- Accountability and transparency will remain the guiding pillars of good governance in all spheres of governance;

- Under-performance, including poor performance, will not be tolerated;

- Maladministration including corruption, nepotism, and cadre deployment of unqualified people, to mention but a few, will not be embraced as a norm in the public service;

- Citizens will be served per the Batho Pele principles, and receive high quality customer services;

- Wasteful expenditure due to poor financial planning, corruption, financial mismanagement and other malpractices will be curbed;

- Government structures will provide tangible evidence of good use of tax payers' money by improving citizens' experiences of government services including basic services provision.

In this context, performance in local government is strictly underpinned by the principles of service excellence and good governance. Public servants in local government must observe the framework described above to ensure optimal performance and fulfil the government's social contract with its citizens as prescribed in the Constitution.

Regulatory Framework for Performance Management in South African Local Government: The Constitution provided the basis for a plethora of statutes that deal with performance management in local government. The Local Government: Municipal Systems Act 32 of 2000 requires that municipalities execute their responsibilities in the most proficient manner possible. It stipulates that municipalities must establish performance management systems to fulfil their constitutional mandate as well as guide them in designing developmental interventions that are responsive to citizens' needs. In so doing, the Act seeks to promote a culture of performance across local government.

The Constitution Act 108 of 1996: Chapter 7 of the Constitution provides the legislative foundation for local government. Section 152 (1) describes its objectives (Davids, 2011). According to Broumels (2014), these are:

(a) To provide an elected inclusive, representative and answerable administration to ordinary citizens;

(b) To provide public services in an equitable manner to all citizens without prejudice;

(c) To advance civic and economic growth;

(d) To develop secure and flourishing living habitats;

(f) To promote public participation in matters of local governance.

While these objectives are useful in guiding local municipalities' development agenda, they require intergovernmental interaction and cooperation. A "culture of cooperation, based on mutual respect and trust" as well as adequate capacity development regarding "financial, technological and human resources" must be established if the set objectives are to be achieved (Reddy, 2001).

White Paper on Local Government: The White Paper on Local Government (1998) provides a framework for performance management to guide municipalities in integrated development and citizen-oriented planning with clear objectives that can be tracked and evaluated over time. It also provides a platform for active public participation in ensuring that municipalities are achieving their targets as per the performance indicators and if this is not the case, to hold them accountable.

Local Government: Municipal Systems Act 32 of 2000: This Act provides an operational framework for local government and sets out the systems that enable it to improve citizens' socio-economic status, by ensuring that they can access essential basic services at an affordable price (Ndlela, 2008). It also details the scope through which local municipalities exercise their power and authority that enables them to determine the framework to deliver essential basic services. The Act specifies vital municipal organisational, planning, participatory and service delivery systems and covers the constitutional rights and responsibilities of 
municipal councils and citizens. From a performance management point of view, the Local Government: Municipal Systems Act, enacted in November 2000.

Requires all municipalities to develop a performance management system set targets, and monitor and review performance based on indicators linked to their IDP publish an annual report on performance for councillors, staff, the public and other spheres of government incorporate and report on a set of general indicators prescribed nationally by the minister responsible for local government conduct an internal audit on performance. Before tabling the report has their annual performance report audited by the AuditorGeneral involve the community in setting indicators and targets and reviewing municipal performance. The Act envisages that municipalities will work resourcefully, be efficient and effective in their work, and meet set performance targets, ultimately leading to excellent service provision that meets citizens' needs and expectations.

The Local Government: Municipal Systems Amendment Act 32 of 2000: This Act became operative after being signed into law in 2011. It envisages a performance management system that aligns municipalities' work with their IDPs and the financial resources necessary to deliver on such plans as well as with the constitutional mandate of serving citizens efficiently and effectively. The Act's objectives are (De Visser, 2011):

- Provide guidance for appointing municipal managers and managers directly answerable to them;

- Set the prerequisites for such appointments including strategies to mitigate any ramifications that may arise because of the process;

- Establish timeframes to conclude performance agreements for municipal managers and managers directly accountable to them;

- Make further provision for the evaluation of the performance of municipal managers and managers directly accountable to them;

- Ensure that all employment and performance contracts are aligned with this Act and regulations made by the Minister of COGTA;

- Ensure that all employee systems and procedures are aligned with the stipulations of the Act as required by the Minister.

Given this background, municipalities are expected to monitor, assess and report on their performance according to set performance targets each financial year. This implies that they must establish performance review mechanisms as per Section 40 of the Act.

Municipal Finance Management Act: This Act was developed to promote effective processes to manage all municipal financial affairs, including those of related institutions in the local government sphere (Kariuki, 2017). Furthermore, the Act strives to inculcate treasury standards for all financial and related matters at the local government level. The purpose of the Act is five-fold (Van der Waldt, 2014): To control municipal fiscal administration to establish prerequisites for resourceful management of the income and expenditure of municipalities and their agencies; to determine responsibilities regarding municipal fiscal administration; to establish a fiscal administration governance structure for municipal entities; to set a frame of reference for municipal financing.

From a performance management point of view, the Act sets the broad framework for financial management at local government level. It also caps expenditure, especially in relation to items not provided for in the annual budget to ensure that local municipalities operate within the prescribed limits. Moreover, it sets parameters to address financial mismanagement within local government and stipulates the consequences for municipal officials who violate any clauses or fail to comply with any of its sections and procedures. One of the Act's shortcomings is that it does not stipulate the minimum qualifications that accounting officers and other municipal personnel should hold to ensure efficient financial management. Skilled personnel are necessary to improve financial administration.

Batho Pele: Customer Service Excellence in the Public Sector: The 1997 White Paper on Transforming Public Service Delivery (Batho Pele) set out citizen-centred principles aimed at ensuring that the government 
provides relevant services that meet the expectation of the public. The eight principles are (Department of Public Service and Administration, DPSA, 2014:1):

Consultation: Citizens should be consulted about the level and quality of public service they receive, and, where possible, should be given a choice about the services, which are provided.

Service Standards: Citizens should know what standard of service to expect.

Access: All citizens should have equal access to the services to which they are entitled.

Courtesy: Citizens should be treated with courtesy and consideration.

Information: Citizens should be given full and accurate information about the public services they are entitled to receive.

Openness and Transparency: Citizens should know how departments are run, how resources are spent, and who oversees services.

Redress: If the promised standard of services is not delivered, citizens should be offered an apology, a full explanation and a speedy and effective remedy; and when complaints are made citizens should receive a sympathetic, positive response.

Value-for-Money: Public services should be provided economically and efficiently to give citizens the best possible value-for-money." The Batho Pele principles thus envisage an active partnership between citizens and government as far as basic services provision is concerned. Municipalities ought to be receiving constant feedback from citizens and other clients so that they can improve their work and build a strong service culture. This requires that they conduct regular customer surveys and feedback meetings to hear citizens' concerns and to report on progress in addressing the challenges. Through these structured feedback mechanisms, municipalities can identify service gaps and address them timeously. Consistency in responding to citizens' concerns is highly likely to minimise civic protest.

Performance Management in Local Government: Current Practice: At present, performance in South African local government is primarily measured on completion of projects (Pollitt, 2013). Most municipalities do not have comprehensive performance management systems (Van der Waldt, 2014) and there are thus no explicit performance objectives except employee performance appraisals (Naff and Riccucci, 2012). Walker and Andrews (2013) contend that such appraisals are limited to job evaluation and are not linked to the employee's contribution to municipal service delivery. To mitigate challenges the Department of Provincial and Local Government (DPLG) published the Performance Management Guide for Municipalities (Department of Provincial and Local Government, 2001). While it provides a framework for performance management processes, it is not implemented by most municipalities (Isaacs, 2016). Compliance is perceived as burdensome and unnecessary, yet municipalities continue to underperform in their service delivery mandate due to a lack of adequate planning and consistency across departments. Thus, addressing socio-economic, socio-political and institutional challenges becomes increasingly difficult for most municipalities. The result is increasing civic protect and a disillusioned citizenry, which does not fully trust their local municipalities to deliver high-quality basic services efficiently and effectively. To remedy this situation, performance management must be strictly adhered to by all municipalities.

Performance Management Challenges in South African Local Government: According to Isaacs (2016), the following challenges beleaguer performance management in local government:

a) Systemic Factors: Which include weak intergovernmental relations, a limited revenue base, and backlogs in basic service delivery?

b) Legislative Factors: Including non-compliance with procedures and protocols;

c) Capacity and Skills: Increased incompetence among personnel in local government;

d) Accountability Systems: Increased corruption, poor community participation mechanisms and poor oversight, especially regarding supply chain management and procurement processes;

e) Political Factors: Inter- and intra-political conflict and polarisation, factionalism, leadership lapses and cadre deployment. Unless these factors are intentionally addressed by municipal leadership supported by the provincial and national departments of cooperative governance (COGTA), they will stifle municipalities' ability to deliver on their constitutional mandate.

Towards Improved Municipal Performance in South Africa: Since the dawn of democracy in South Africa, significant municipal restructuring has occurred to enable local government to optimally serve citizens. This 
process began in the early 1990s, supported by a plethora of legislative instruments which saw the number of municipalities decrease from 843 to 283 (Reddy et al., 2012). Furthermore, the Demarcation Board has incorporated some areas with others for ease of administration and the provision of essential services (Meyiwa et al., 2014). Kariuki (2017) argues that other statutes such as the Local Government: Municipal Systems Act 32 of 2000 and Local Government: Municipal Structures Act 117 of 1998 has been instrumental in creating a standardised performance-oriented municipal framework. Whilst it is largely acknowledged that local municipalities have played a significant role in entrenching the benefits of democracy, the hierarchical arrangement of the three spheres of governance reinforces the notion of autonomy. Municipalities perceive that they can chart their own path independent of their provincial and national counterparts.

This autonomous nature of local municipalities weakens their capacity to meet citizens' needs and establish programmes that match their aspirations (Minnaar, 2010). Given continued poor performance and maladministration, citizens' confidence in local government is waning fast. If local government is to retain its authenticity, it will need significant political support to ensure that its performance is not compromised. Reddy et al. (2012), case study of Mandeni Municipality found that even though the municipality enjoys autonomy, it is facing substantial developmental challenges. With a minimal revenue base and a rapidly growing population as well as strained socioeconomic conditions, this local municipality is barely able to achieve basic developmental goals and other performance-related targets. The case study provides useful lessons on municipal performance in South Africa. These include inter alia:

a) Merging smaller municipalities with larger municipalities should be carefully considered as it can hamper the wellbeing of the local populace, especially where revenue is not shared proportionately, ultimately affecting the performance of the municipalities involved;

b) The provincial department responsible for local government should provide adequate resources to local municipalities, especially human resources. Like many municipalities, Mandeni Municipality lacks skilled personnel to execute its mandate effectively, which compromises its capacity to perform optimally. Financial and technical challenges need to be addressed;

c) Connected to the above point, the provincial department and local municipalities must endeavour to retain skilled and competent personnel by ensuring a conducive, organisational culture. Organizational cultures that value competency and hard work are known to attract and retain highly skilled personnel;

d) Robust M \& E systems should be adopted to track the implementation of municipal projects and related activities and feedback mechanisms should be set up to inform project improvement and overall municipal performance and governance;

e) Revenue collection mechanisms should be strengthened to ensure that all local municipalities, irrespective of their size, have the necessary financial resources for their operations; otherwise their performance will be compromised. Ultimately, ordinary citizens bear the brunt.

\section{Methodology}

Research Design: The study adopted qualitative approaches to collect data from $\mathrm{M}$ \& $\mathrm{E}$ practitioners in selected municipalities in KwaZulu-Natal. This yielded a valuable snapshot of the various dynamics at local government level in terms of M \& E personnel's capacity to deliver on their mandate, that is, providing quality information from various government programmes to assess municipal performance in equitably delivering citizen-responsive basic services. The two approaches were deemed appropriate as they provided critical information for triangulation purposes. Triangulation of data provides a sound understanding of human behaviour, problems and characteristics and thus enhances confidence in the validity of the findings (Jesperson and Wallace, 2017).

Sampling of Respondents: To generate a representative sample, the following criteria were adopted to guide the selection of participating municipalities:

a) Geographical size of the municipality;

b) Functionality of M \& E units/departments;

c) Availability and functionality of service delivery departments providing a range of public services such as education, health, water and sanitation;

d) Population of the municipality;

e) Geographical characteristics of municipalities - urban, rural and peri-urban areas; 
f) Revenue base;

g) Audit report - good or bad.

Using these criteria, 16 municipalities were chosen to participate in the study and comprised of a metro (Category A), five district municipalities (Category C) and ten local municipalities (Category B). The primary reason for choosing municipalities across the spectrum was that the study sought to understand $\mathrm{M} \& \mathrm{E}$ skills capacity within $M$ \& E units across a range of local government departments in municipalities in the Province of KwaZulu-Natal. This Province was purposively selected because it has a combination of municipalities with varying dynamics in terms of geographical, economic and social factors. This combination provided a rich tapestry for the study in its efforts to understand M \& E practices in these municipalities. Both probability and non-probability sampling methods were used to select an appropriate sample for the study.

In terms of the probability sampling technique, multi-stage sampling was applied to generate a list of local municipalities. This enabled the researcher to select a sample of municipalities that he believed to be representative and unbiased, thereby enhancing the validity and reliability of the data gathered. A list of all $\mathrm{M}$ \& E personnel from the selected municipalities was obtained from COGTA and the same technique was utilized to generate a list of $M$ \& E personnel working in $M$ \& E departments and units performing $M$ \& E functions at the selected municipalities. The functionaries were first stratified according to their educational qualifications and the number of years they had served in their capacity as M \& E officers. A systematic sampling technique was then applied to distinguish the selected M \& E personnel according to their age, gender, race, education levels, and years of service as municipal functionaries and experience as $\mathrm{M}$ \& $\mathrm{E}$ practitioners.

Data Collection: For the purposes of this article, qualitative data is utilised. This data was gathered via documentary review, and semi-structured and in-depth key informant interviews as well as participatory research techniques such as focus group discussions and Venn diagrams. This was important in ensuring that the perspectives of $\mathrm{M}$ \& E personnel with different levels of experience and educational credentials were captured, and provided equal chances to male and female $M \& E$ officers from various population groups (Whites, Black Africans, Indians and Coloureds) to be selected to participate in the study. Venn diagrams are useful visualisation techniques that enable researchers and respondents alike to recognize any relationships that exist on an issue, problem or situation including the power relations among respondents, institutional arrangements between organisations and decision-making processes in an institution (Radhakrishna et al., 2016).

Data Analysis: Once collected, the qualitative data was analysed thematically, where data was coded according to emerging themes. Interviews and focus group discussions were digitally recorded and transcribed immediately. The transcribed information was stored safely and confidentially in a pass-word controlled computer only accessible to the researcher.

\section{Findings}

Laxity among Municipal Functionaries and its Impact on Municipal Performance in Fulfilling its Constitutional Mandate: Failure to enforce performance management processes has led to laxity and limited interest in excelling among municipal functionaries. One respondent claimed: "You know our PMS (performance management system) was established long ago...but who knows about it here ...so we're not worried about performance as such...we know we must do our job...but excelling is not in the equation....so we relax and just flow with the flow...and that relaxing has made most of us lazy...caring for nothing other than themselves." Whilst most of the municipalities involved in the study have a performance management system, it is relatively unknown by most employees. In terms of Section 55(1) of the Local Government: Municipal Systems Act of 2000, municipal managers should ensure that municipal performance is enforced. Failure to take this responsibility seriously has severe implications for the execution of a municipality's constitutional mandate. These include: Inability to measure progress towards realizing the objectives and targets set in the IDP; Limited oversight of the monitoring and technical support mechanisms designed to guide organizational and individual performance within the local municipality; Limited remedial action from municipal leadership to sanction non-performance or poor performance; Non-alignment of budget 
information to outputs that can measure the municipality's performance. There is a dire need to ensure that performance management is consistently enforced in municipalities and for municipal leadership to follow through with the practices required to reduce incidences relating to non-performance and poor performance.

Lack of Clarification on the Roles and Responsibilities of Municipal Functionaries: Because of inconsistent enforcement of performance management, some municipal functionaries are unaware of their roles and responsibilities. According to one respondent, "measuring individual performance is challenging when colleagues are unclear about their duties." Regulation 7 of the 2001 Performance Regulations requires that every municipality develop a performance management system. It comprises a performance framework that describes how the municipality's cycle and processes of performance planning, monitoring, measurement, review, reporting and improvement will be conducted, organized and managed, and sets out the roles and responsibilities of different stakeholders, including employees. If municipal functionaries do not understand their roles and responsibilities, it is difficult to plan and monitor their work, whilst at the same time periodically measuring and reviewing performance in terms of key performance indicators and other targets for efficiency and effectiveness.

Performance Management is not taken seriously in Municipalities: There was overwhelming agreement among the $M \&$ E practitioners that participated in the study that performance management is not taken seriously in municipalities. According to one respondent, most employees perceive that performance management is a quick way to obtain rewards: "Staff feel that they are obliged to receive a reward for performance, even though they are being paid to do their jobs this is not correct because it creates a culture of entitlement in the organization....as the desire to do more as an employee and excel beyond their present performance." Whilst it is important to recognize individual efforts that enhance overall unit or departmental performance, the processes for recognition of outstanding efforts should be clearly communicated to staff. This is important to avoid expectations that cannot be fulfilled, especially if performance is not linked to rewards as a norm in the organisation.

Challenges Due to Lack of Adequate Supervision and Management of Staff: Connected to the above it was claimed that supervisors do not adequately manage staff performance. Municipal staffs are permitted to set their own key performance areas, without aligning with the organizational strategy. This creates performance measurement challenges. Due to limited supervision, staffs are left to decide what constitutes performance and in most cases, it is about the work they do and there is no motivation to go the proverbial extra mile. As noted above, key performance indicators are often not aligned with the overall organizational strategy. It is thus challenging to measure a staff member's contribution to organisational effectiveness and efficiency. One respondent claimed: "Staffs are not motivated to do more than what is in their contracts there is no incentive to go the extra mile, so when performance is kind of left to the individual's idea of key performance area, measuring our collective performance is almost impossible." Considering the above, it can be argued that there should be a single performance management system for all levels of staff, which must be aligned to the strategies of the organisation and strictly enforced through supervision.

Internal Organizational Factors Impeding Effective Performance Management in Municipalities: According to the $M$ \& E practitioners, the following internal organisational factors impede effective performance management in municipalities.

Abdication of Responsibilities: Municipal managers do not strictly enforce performance management in most KwaZulu-Natal municipalities.

Limited Supervision of Staff: Departmental heads do not provide consistent and adequate supervision to their subordinates, thereby leaving them to their own description of what constitutes excellence;

Misalignment of Supervision Plans for an Individual with the Organisational Plan: When an individual's performance plan is not aligned to the organisational strategy, it is impossible to correctly measure how he/she is contributing to the realisation of organizational goals.

Misconception of the Meaning of Performance Management: Performance management is perceived to be a way to obtain rewards rather than a tool to enhance results through effective accountability. 
Limited Consistency in Enforcing Performance Management by Senior Municipal Political Leadership: Given the increasing evidence of maladministration, corruption and wasteful expenditure due to bad planning among other aspects, municipal leadership, meaning Executive Mayors and their deputies are not sufficiently concerned about performance management. If municipal leadership were to be consistent in ensuring zero tolerance for non- or poor performance, individual employees' level of responsibility for their performance is likely to improve. These internal factors need to be addressed by senior municipal leadership in collaboration with departmental heads to enhance performance management in municipalities.

How Can the Internal Challenges Experienced by Municipalities Be Mitigated to Foster a Culture of Performance Management: According to the study participants, the internal issues can be addressed as follows: Design performance management applications, and improve reporting requirements to AuditorGeneral standards. Apply performance management as a strategic management technique that links various organisational elements of performance in municipalities and local government in general. Enforce performance management by creating a culture of performance, which comes from an understanding of the work staff are doing and how it fits into the bigger picture (the overall municipal strategy). Design and implement turn-around strategies that can be monitored for key performance indicators in areas where poor/non-performance has been noted; Establish an automated Performance Management System linked to the financial system. This is critical because the financial resources used to enhance employees' professional capacity can be tracked to establish the impact of the investment on overall organisational performance. Any gaps in terms of investment made and performance results should be addressed.

Importance of Enforcing Performance Management in Municipalities: From the municipal M \& E practitioners' perspective, performance management facilitates consistent tracking of the extent to which the objectives of government interventions have been achieved. Shortcomings can be identified and remedial action can be developed and implemented. Other benefits of performance management in the context of $M$ \& E include: High level performance of individual municipal staff; An improved organisational culture where performance is accepted as the norm; Limited instances of non-performance and poor-performance among municipal staff; Accurate presentation of municipal results as different units in the municipality collaborate with the M \& E unit to enable data collation and analysis leading to truthful reporting of the state of affairs; Improved morale among municipal staff as they enhance their individual performance, leading to the achievement of the municipality's overall goals; Improved management of municipal interventions, especially in relation to measuring the implementation and impact of public policies such as those relating to service delivery.

\section{Conclusion}

A performance management system is advantageous to a municipal $\mathrm{M}$ \& E system as it detects any institutional challenges impeding operational efficiency whilst providing direction towards better planning of developmental goals. It also provides a mechanism to manage expectations and enhances the municipality's accountability to local citizens. It also provides early cautionary indications to recognize challenges in implementing development plans and offers suitable evidence-based information for enhanced and qualitative decision making. It is important to ensure the alignment of individual key areas of performance with those of the municipality and to harmonize such efforts to accomplish the ultimate objective. This will assist municipal employees to understand the expectations of their employer and the quality of work expected. It also enables them to comprehend key areas of accountability.

A performance management system helps to determine whether performance goals are being realized and take informed decisions within employees' scale of aptitudes. Citizens and other stakeholders utilising municipal services are becoming increasingly interested in determining how well municipalities are executing their functions. The objective is to transit from basic fiscal commentary towards an all-inclusive reporting on organizational performance and development. Performance reports provide a mechanism for management to report to the organization's investors on its resourcefulness and operational efficacy. A culture of performance management has to be instilled and legally enforced in local government in South Africa to ensure that the desired municipal objectives are attained. Fundamental to the process is the 
mandatory political and management will to ensure a vibrant performance management system in the expansive context of good governance.

\section{References}

AQUINAS, H. (2013). Performance Management. Edinburgh Business School.

BROUMELS, M. (2014). The Local Government Handbook South Africa 2014. A complete guide to municipalities in South Africa. Claremont. Media Press.

BUSSIN, M. (2017). Performance Management REBOOT: Fresh perspectives for the changing world of work, KR Publishing.

DAVIDS, G. J. (2011). Local Government capacity challenges in post apartheid South Africa: Lessons learnt. African Journal of Business Management, 5, 3570-3576.

DE VISSER, J. (2011). Implementing the Municipal Systems Amendment Act. Local Government Bulletin, 13, 10-11.

DEPARTMENT OF PROVINCIAL AND LOCAL GOVERNMENT. (2001). Performance management guide for municipalities. Pretoria, Government Printer.

HELLQVIST, N. (2011). Global Performance Management: A Research Agenda. Management Research Review, $34,927-948$.

ISAACS, J. D. (2016). The impact of transformational leadership on performance management: a South African local government case study. Stellenbosch: Stellenbosch University.

JESPERSON, L. \& WALLACE, C. (2017). Triangulation and the importance of establishing valid methods for food safety culture evaluation. Food Research International, 100, 244-253.

KARIUKI, P. (2017). Developing a Human Resource Framework for Monitoring and Evaluation Personnel in Selected Municipalities of KwaZulu-Natal, University of KwaZulu-Natal.

MERCER, M. (2015). Global Performance Management Survey [Online].

MEYIWA, T., NKONDO, M., CHITIGA-MABUGU, M., SITHOLE, M. \& NVAMNJOH, F. (2014). State of the Nation. South Africa 1994-2014: A Twenty-year Review. Cape Town. HSRC Press.

MINNAAR, F. (2010). Strategic and Performance Management in the Public Sector.

NAFF, K. C. \& RICCUCCI, N. M. (2012). Personnel management in government: Politics and process, Routledge.

NDLELA, N. (2008). Local Government and Traditional Leadership: A Case Study of Umgungundlovu, Umzinyathi, Uthukela and Amajuba District in KwaZulu Natal.: University of KwaZulu-Natal.

NIXON, A. (2011). A Handbook for Measuring Employee Performance. Office of Personnel Management, US Government [Online].

POLLITT, C. (2013). The logics of performance management. Evaluation, 19, 346-363.

RADHAKRISHNA, V., KUMAR, P. V. \& JANAKI, V. (2016). A novel approach for mining similarity profiled temporal association patterns. arXiv preprint arXiv:1604.05272.

REDDY. (2001). Intergovernmental relations in South Africa. Politeia, 20, 21-39.

REDDY, NZIMAKWE, T. \& RAMLUCKEN, S. (2012). Local government restructuring and transformation in South Africa. Dimensions of local governance, 10, 43.

SONNENTAG, S. \& FRESE, M. (2003). Performance concepts and performance theory. Psychological management of individual performance, 1.

VAN DER WALDT, G. (2006). Managing local government performance: key considerations and challenges. Journal of Public Administration, 41, 128-143.

VAN DER WALDT, G. (2014). Implementation challenges facing performance management systems in South African municipalities: selected cases.

WALKER, R. M. \& ANDREWS, R. (2013). Local government management and performance: A review of evidence. Journal of Public Administration Research and Theory, 25, 101-133. 